Artigo

\title{
Espreitando a emergência da Modelagem Matemática na Educação Matemática $^{1}$
}

\author{
Peeking into the emergence of Mathematical Modeling in Mathematics Education \\ Echando un vistazo al surgimiento del modelado matemático en la educación \\ matemática
}

\author{
Maria Carolina Machado Magnus ${ }^{2}$ \\ [0000-0002-2834-9293] \\ Ademir Donizeti Caldeira ${ }^{3}$ \\ [0000-0003-0290-9851]
}

\begin{abstract}
Resumo
O presente artigo tem por objetivo analisar quais foram as condições de possibilidade para que o discurso da Modelagem Matemática emergisse na Educação Matemática brasileira. Para isso, lançou-se mão de aportes teórico-metodológicos vinculados às teorizações do filósofo Michel Foucault. O material analítico abrange teses e dissertações defendidas no Brasil no período entre os anos de 1976 e 1999, as quais tematizaram a Modelagem Matemática na Educação Matemática. A análise desses estudos evidenciou que a emergência do discurso da Modelagem ocorre em meio a uma crise no ensino de Matemática. Essa crise foi problematizada, no presente artigo, a partir do seguinte enunciado: "Os alunos têm dificuldade na aprendizagem da Matemática". A dificuldade na aprendizagem de Matemática é justificada pelo argumento de que os alunos não teriam base, uma vez que não aprenderam os conteúdos ensinados nos anos anteriores. Tal asserção evidencia as noções de norma, ordem, sequência e hierarquia dos conteúdos matemáticos. Sendo assim, a emergência do discurso da Modelagem operaria um deslocamento na maquinaria curricular. Ou seja, as práticas seriam guiadas pela contingência, pelo caos em detrimento da ordem, da hierarquia, da sequência e da norma. Porém, ela não criaria fissuras ou trincas no discurso curricular; pelo contrário, legitimaria a busca por táticas efetivas que incidam positivamente no processo de ensino e aprendizagem. Desta forma, a Modelagem funcionaria como uma engrenagem na busca pelo melhor funcionamento daquilo que está posto em termos de Educação Matemática no país.
\end{abstract}

Palavras-chave: Modelagem Matemática. Currículo. Aprendizagem. Ensino. Emergência.

\begin{abstract}
The present article aims to analyze the conditions that made it possible for Mathematical Modeling reasoning to arise within Brazilian Mathematical Education. For such, theoretical and methodological inputs linked to theories by the philosopher Michel Foucault have been used. The analytic material contains theses and dissertations defended in Brazil between the years 1976 and

\footnotetext{
${ }^{1} \mathrm{O}$ presente artigo é um recorte da pesquisa de doutorado da primeira autora, sob orientação do segundo, no âmbito do Programa de Pós-Graduação em Educação da Universidade Federal de São Carlos.

2 maria.carolina.magnus@ufsc.br, Doutora em Educação, Professora no Departamento de Educação do Campo da Universidade Federal de Santa Catarina, Florianópolis-SC, Brasil.

${ }^{3}$ mirocaldeira@gmail.com, Doutor em Educação, Professor associado IV no Departamento de Metodologia de ensino da Universidade Federal de São Carlos, São Carlos-SP, Brasil.
} 
1999 whose theme was Mathematical Modeling in Mathematics Education. The analysis of such studies made it evident that the emergence of the Modeling reasoning comes in the midst of a crisis in the teaching of Mathematics. This crisis has been discussed, in the present article, from the following statement: "The students have difficulties learning Mathematics". The difficulty for learning Mathematics is justified with the argument that students wouldn't have a foundation, since they haven't learnt the contents taught in the previous years. Such claim highlights the notions of rule, order, sequence and hierarchy of mathematical contents. Thus, the emergence of a Mathematical Modeling reasoning would operate a displacement on the curriculum machinery. That is, practice would be guided by contingency, by caos to the detriment of order, hierarchy, sequence and the rule. However, it wouldn't create fissures or gaps in the curricular reasoning; on the contrary, it would legitimate the search for effective tactics that positively incide on the process of teaching and learning. In that way, Modeling would work as gearing towards the search for the best operation of that which is established in terms of Mathematics Education in the country.

Key words: Mathematical Modeling. Curriculum. Learning. Ensino. Emergence.

\title{
Resumen
}

Este artículo tiene analisar como objetivo analizar cuáles fueron las condiciones de posibilidad para que el discurso del Modelado Matemático surja en la Educación Matemática Brasileña. Para ello, se utilizaron contribuciones teórico-metodológicas vinculadas a las teorizaciones del filósofo Michel Foucault. El material analítico abarca tesis y disertaciones defendidas en Brasil en el período comprendido entre 1976 y 1999, que temáticaron a el modelado matemático en la educación matemática. El análisis de estos estudios mostró que el surgimiento del discurso de modelado ocurre en medio de una crisis en la enseñanza de las matemáticas. Esta crisis fue problemática en el presente artículo, a partir de la siguiente declaración: "Los estudiantes tienen dificultades para aprender matemáticas". La dificultad para aprender matemáticas se justifica por el argumento de que los estudiantes no tendrían fundamento, ya que no aprendieron los contenidos enseñados en años anteriores. Esta aserción destaca las nociones de norma, orden, secuencia y jerarquía de contenido matemático. Por lo tanto, el surgimiento del discurso de modelado permitiría un desplazamiento en la maquinaria curricular. Es decir, las prácticas se guiarían por la contingencia, el caos en detrimento del orden, la jerarquía, la secuencia y la norma. Sin embargo, no crearía grietas o grietas en el discurso curricular; por el contrario, legitimaría la búsqueda de tácticas efectivas que afecten positivamente el proceso de enseñanza y aprendizaje. De esta manera, el Modelado actuaría como un engranaje en la búsqueda del mejor funcionamiento de lo que se pone en términos de Educación Matemática en el país.

Palabras claves: Modelado matemático. Reanudar. Aprendizaje. Enseñanza. Emergencia.

\section{Pensar diferente... da insatisfação à constituição de uma pesquisa}

\author{
Mas o que é filosofar hoje em dia \\ - quero dizer, a atividade filosófica - \\ senão o trabalho crítico sobre o próprio pensamento? \\ Senão consistir em tentar saber de que maneira e até onde seria possivel \\ pensar diferentemente em vez de legitimar o que já se sabe?
}

(FOUCAULT, 2014b, p. 14).

Pensar diferente sobre o próprio pensamento... Foi, afinal, a insatisfação com o já sabido que nos possibilitou colocarmo-nos em movimento para arriscarmos pensar 
diferente. Em vez de legitimar um discurso que circula como verdadeiro em diversos espaços - escolas, universidades, currículos, dentre outros -, mobilizamo-nos e deslocamos nosso próprio pensamento para a árdua tarefa de pensarmos e problematizarmos coisas outras.

A Modelagem Matemática é um discurso legítimo e legitimado na/pela Educação Matemática e, de alguma maneira, ela tem nos inquietado, desestabilizando-nos, desassossegando-nos e nos desafiado a pensar criticamente sobre as suas e as nossas pretensões de verdades. Portanto, é sobre esse solo firme que este artigo pretende causar algumas fissuras, talvez trincas, quiçá uma rachadura ou uma fenda.

Nos últimos anos, temos nos debruçado, enquanto pesquisador/a e professor/a, aos estudos sobre Modelagem Matemática na Educação Matemática. Esse discurso tem circulado e colocado em funcionamento discussões sobre o papel da Matemática na sociedade, a sua importância para o desenvolvimento científico e tecnológico, seus usos no cotidiano e, também, sua relevância para a constituição de um cidadão crítico. Muitas pesquisas têm apontado o uso da Modelagem como uma possibilidade de (re)significação das aulas de Matemática, tornando os alunos interessados pelo aprendizado de seus conteúdos, já que a Modelagem poderia mostrar a utilidade dessa disciplina, suas relações com outras áreas, outros conhecimentos, outras realidades.

Ainda, as atividades de Modelagem seriam capazes de responder àquelas inquietantes perguntas: "para que serve isso?", "onde vou utilizar isso?", "para que aprender Matemática?". Consequentemente, "seria ela, a Modelagem, uma possibilidade para "salvar" o ensino de Matemática?". Será que nós, enquanto pesquisador/a e professor/a, alinhados a esse discurso, estaríamos (re)produzindo e ajudando a colocar em funcionamento essas situações em sala de aula e em nossas pesquisas? Estaríamos contribuindo com as solidificações desse discurso? Estaríamos sendo salvacionistas? Provavelmente!

Portanto, foi o trabalho crítico sobre o nosso próprio pensamento que nos possibilitou colocarmos em suspeição as cristalizações daquilo que é posto em circulação e funcionamento e, principalmente, sobre aquilo que estávamos (re)produzindo. Ao pensarmos de outra maneira, começamos a levantar algumas problematizações e inquietações. Dito de outra forma, será que essas discussões engendradas no desenvolvimento das atividades de Modelagem não acabam por operar com pretensões à verdade única (CORAZZA, 2012)? Será que essas discussões geram criatividade? Será que as aulas e as pesquisas têm sido desenvolvidas como um território singular (CORAZZA, 2012)? Será que ao tentar produzir um espaço de criação não tem sido gerado um espaço de legitimação de um discurso hegemônico? Quanta inquietação...

Mesmo aparentemente diferentes, não seriam essas atividades constituintes de uma "aula-clichê"? (CORAZZA, 2012). Não estaríamos em busca de uma receita sobre "como dar uma aula"? (CORAZZA, 1996), uma boa aula? Não estaríamos legitimando o enunciado que circula na Educação Matemática sobre a "importância de trabalhar com a 'realidade' do aluno" (DUARTE, 2009)? Não estaríamos atestando que "o uso da Modelagem Matemática na(s) forma(s) de vida escolar suscita o interesse do aluno pela Matemática escolar" (QUARTIERI, 2012)? Ao tentar produzir um território singular, não estaríamos produzindo o mesmo território?

No decorrer de nossas carreiras e em decorrência de pesquisas realizadas no âmbito de nosso Grupo de pesquisa, começamos a suspeitar desse discurso, a questioná-lo. 
Algumas indagações foram emergindo: "por que ensinar Matemática a partir desse discurso?", "por que a relação entre Matemática e outras áreas do conhecimento passa a ser discutida na Educação Matemática?", "por que esse discurso vira 'assunto' entre os educadores matemáticos?", "por que trabalhar com Modelagem?", são tantos os porquês...

Foram essas indagações que geraram a insatisfação com o já sabido, dando forma à pesquisa que gerou o presente artigo. Concordamos com Corazza (2007), assim, quando a autora nos diz que se alguém está satisfeito com algo não há por que, para quê e o quê pesquisar, uma vez que a pesquisa nasce da insatisfação. Ainda de acordo com Corazza (2007, p. 109),

para alguém sentir e aceitar que está insatisfeita/o é necessário que, em outra esfera que não a dos dados ditos empíricos, sua experiência de pensamento engaje-se na criação de uma nova política das verdades, colocando em funcionamento outra máquina de pensar, de significar, de analisar, de desejar, de atribuir e produzir sentidos, de interrogar em que sentidos há sentidos.

A insatisfação tornou-se, dessa forma, o mote para que a presente pesquisa fosse desenvolvida. Insatisfação que coloca em funcionamento outras formas de pensar, de significar, de analisar o discurso da Modelagem. Essa inquietação nos colocou em movimento para pensarmos, refletirmos, investigarmos sobre as condições de possibilidade para que o discurso da Modelagem Matemática emergisse na Educação Matemática brasileira. Ou seja, por que esse discurso ganha visibilidade entre pesquisadores/as e professores/as?

\section{Das ferramentas teórico-metodológicas}

A experiência, a possibilidade de que algo nos aconteça ou nos toque, requer um gesto de interrupção, um gesto que é quase impossivel nos tempos que correm: requer parar para pensar, parar para olhar, parar para escutar, pensar mais devagar, olhar mais devagar, e escutar mais devagar; parar para sentir, sentir mais devagar, demorar-se nos detalhes, suspender a opinião, suspender o juízo, suspender a vontade, suspender o automatismo da ação, cultivar a atenção e a delicadeza, abrir os olhos e os ouvidos,

falar sobre o que nos acontece, aprender a lentidão, escutar aos outros, cultivar a arte do encontro, calar muito, ter paciência e dar-se tempo e espaço.

(LARROSA, 2002, p. 24)

Ao desestabilizarmos um solo firme, em busca dos porquês, foi preciso que suspendêssemos nossas opiniões, juízos, vontades, automatismos, pretensões e verdades sobre um discurso legítimo e legitimado no campo da Educação Matemática. Para tanto, foi necessário aprendermos a lentidão, a escuta, a paciência e, principalmente, o demorarse nos detalhes.

\section{Do material analítico}

As teses e dissertações selecionadas para compor o material analítico tiveram como foco a Modelagem Matemática e foram defendidas no Brasil no período entre os anos de 
1976 e 1999. A escolha por este período deve-se à consideração de que essa foi a fase de emergência e instituição da Modelagem enquanto um discurso tido como verdadeiro (MAGNUS, 2018). A escolha por essas pesquisas justifica-se pelo fato de que na mencionada fase o principal local de discussão e circulação desse discurso foi por meio da produção científica, materializada em teses e dissertações.

A universidade é local de produção, controle e seleção dos discursos que entram em ordem, em circulação, em funcionamento. Cada sociedade possui seus regimes de verdade e na universidade esses regimes podem ser encontrados em diversos espaços: graduação, pós-graduação, grupos de estudo e pesquisa etc. Em nossa pesquisa, privilegiamos os espaços dos cursos de Pós-Graduação, uma vez que esses cursos são tidos como local onde os discursos são acolhidos como verdadeiros a partir das técnicas que os caracterizam como científicos. Eles se diferenciariam dos discursos tidos como falsos, pois os cursos do meio acadêmico têm o encargo e a credibilidade para dizer o que funciona como verdadeiro e o que está relegado a uma exterioridade selvagem. A produção do saber, dessa forma, está entrelaçada ao poder, e esses cursos têm o poder de dizer o que é tido como verdadeiro e o que é tido como falso.

As teses e dissertações selecionadas para compor o material analítico "são investigações produzidas e avaliadas em cursos qualificados de Pós-Graduação do país e reconhecidos pelo Ministério de Educação - MEC" (QUARTIERI, 2012, p. 72). Esses cursos, ao serem qualificados e reconhecidos pelo MEC, dão aos saberes produzidos nas universidades legitimidade e o reconhecimento de que são tidos como verdadeiros.

Após a seleção dos materiais analíticos, debruçamo-nos sobre eles a fim de escrutinarmos regularidades que, de algum modo, remetessem à emergência do discurso em estudo. Para tanto, buscamos analisar, a partir das enunciações que compõem as teses e as dissertações, como o disperso se entrelaça, cria certa regularidade, constitui enunciados e, consequentemente, faz emergir e coloca em circulação e funcionamento o discurso da Modelagem Matemática na Educação Matemática.

\section{Do enunciado}

Mas, o que é enunciado? Em uma perspectiva foucaultiana, não há espaço para responder a essa pergunta, já que, para tal concepção, não há essência das coisas, não há algo em si. Ainda assim, mas Foucault assume o risco das definições e descreve o seu entendimento de enunciado. Primeiro, ele o define pela oposição àquilo que os gramáticos chamaram de frase, os lógicos designaram por proposição e os analistas tentaram demarcar por speech act (GREGOLIN, 2004). Sob essa lógica, encontramos enunciados onde não podemos reconhecer uma frase: "uma árvore genealógica, um livro contábil, as estimativas de um balanço comercial são enunciados: onde estão as frases?" (FOUCAULT, 2014a, p. 99), ou seja, não se encontra um enunciado por meio dos constituintes da frase (sujeito-verbo-predicado) (GREGOLIN, 2004); ao contrário da proposição, para os enunciados não há formulações equivalentes, por exemplo, 'ninguém ouviu' e 'é verdade que ninguém ouviu' possuem uma mesma estrutura proposicional e não podem ser consideradas diferentes. "Ora, enquanto enunciados, estas duas formulações não são equivalentes nem intercambiáveis" (FOUCAULT, 2014a, p. 97). A primeira (ninguém ouviu) pode ser encontrada em um livro de romance e a segunda (é verdade que ninguém ouviu) em um fragmento de um diálogo. 
Embora se trate de uma mesma estrutura proposicional, seus caracteres enunciativos são distintos. Encontramos mais enunciados do que os atos de linguagem que podemos isolar, de maneira que "é preciso, frequentemente, mais de um enunciado para efetuar um speech act: [...] seria difícil contestar, em cada uma delas, o status de enunciado, sob o pretexto de que são todas atravessadas por um único e mesmo ato ilocutório" (IBIDEM, p. 100).

Se o enunciado pertence ou não ao mesmo gênero da frase, da proposição e do ato de linguagem, como podemos defini-lo? Para Foucault o enunciado não é uma estrutura, ele é mais onipresente, mais tênue, menos carregado de determinações. Nessa conformidade, é preciso admitir que qualquer série de signos, de grafismos ou de traços é suficiente para constituir um enunciado. O enunciado é "uma função que cruza um domínio de estruturas e de unidades possíveis e que faz com que apareçam, com conteúdos concretos, no tempo e no espaço" (FOUCAULT, 2014a, p. 105).

Essa função enunciativa possui suas condições de existência, regras que a controlam e um campo em que se realizam. Um enunciado para existir não tem diante de si um correlato ou uma ausência de correlato, por exemplo, "a montanha de ouro está na Califórnia" (FOUCAULT, 2014a) não possui um referencial que possa ser encontrado em um mapa geográfico, ou em um manual de viagem, mas, pode ser encontrado em uma obra de ficção. Seu referencial não é constituído de "coisas", de "fatos", de "realidades" ou de "seres", mas de leis de possibilidade. O referencial do enunciado forma o lugar, a condição, o campo de emergência (FOUCAULT, 2014a, p. 110). O enunciado é um espaço vazio que pode ser preenchido por diferentes sujeitos que "podem vir a tomar posição e, assim, ocupar esse lugar quando formulam o enunciado" (MACHADO, 2007, p. 151).

Um enunciado não existe "isoladamente, como pode existir uma frase ou uma proposição. Para que estas se tornem enunciados é preciso que sejam um elemento integrado a um conjunto de enunciados" (IBIDEM, p. 151). Além disso, outra condição de existência de um enunciado é a sua materialidade, que é de ordem institucional. "Uma frase dita na vida cotidiana, escrita em um romance, fazendo parte do texto de uma constituição ou integrando uma liturgia não constitui um mesmo enunciado. Sua identidade depende de sua localização em um campo institucional" (IBIDEM, p. 152).

Por fim, o que determina um enunciado, ou a função enunciativa, é "o fato de ele ser produzido por um sujeito, em um lugar institucional, determinado por regras sóciohistóricas que definem e possibilitam que ele seja enunciado" (GREGOLIN, 2004, p. 26).

Uma vez que o enunciado é considerado a unidade elementar do discurso, em que consiste a enunciação? Para Foucault (2014a), a enunciação é um acontecimento que não se repete, que possui singularidade situada e datada, que não se pode reduzir. Diremos que há enunciação cada vez que um conjunto de signos for emitido (FOUCAULT, 2014a). A enunciação pode ser recomeçada e/ou reevocada enquanto o enunciado pode ser repetido. Neste trabalho, estamos considerando enunciação o que os autores escreveram em seus artigos, relatos de experiência, tese e dissertação. Cada autor emite um conjunto de signos, que não se repetem, mas existe regularidade entre eles. Dito de outra forma, o conjunto das enunciações, dos signos emitidos pelos autores, forma um enunciado. Consideramos que a enunciação é a unidade elementar do enunciado. Após o levantamento dos enunciados, tivemos que olhar, lançar luzes e analisá-los. Mas, como fazer isso? Como olhar? O que olhar? Quais estratégias utilizar? 


\section{Dos olhares analíticos}

Nossos olhares foram constituídos a partir de um conjunto de estratégias e de alguns cuidados metodológicos. Ao escrutinarmos o material analítico, tivemos o cuidado de "[...] analisar o dictum como um monumento e não como um documento. Isso significa que a leitura (ou escuta) do enunciado é feita pela exterioridade do texto, sem entrar propriamente na lógica interna que comanda a ordem dos enunciados" (VEIGA-NETO, 2007, p. 104, grifos do autor). Ou seja, olhamos para as descontinuidades em sua exterioridade, por meio daquilo que cerca e sustenta o enunciado.

Ainda, a análise monumental não está à procura de uma suposta verdade, "nem mesmo busca uma essência original, remota, fundadora, tentando encontrar, nos não-ditos dos discursos sob análise, um já-dito ancestral e oculto" (VEIGA-NETO, 2007, p. 98). Ao analisarmos as descontinuidades não buscamos um não dito, pois "o que nos interessa descobrir já está lá; basta saber ler" (VEIGA-NETO, 2007, p. 105).

A análise foi realizada, assim, sob um já dito. Isto é, analisamos o dito, o que está escrito nas teses e nas dissertações, e não a intenção que tiveram de dizer ou aquilo que poderia ser dito, que estaria oculto em sua escrita. Analisamos o que foi dito e as condições que possibilitaram que aquilo fosse dito e não outra coisa em seu lugar. Ou seja, não buscamos o não-dito, pois "até mesmo os silêncios são apenas silêncios, para os quais não interessa procurar preenchimentos; eles devem ser lidos pelo que são e não como nãoditos que esconderiam um sentido que não chegou à tona do discurso" (VEIGA-NETO, 2007, p. 98).

Nessa perspectiva, o olhar que lançamos sobre o material empírico não buscou "descobrir verdades ocultas, mas tornar visível exatamente o que já está visível" (ARTIÈRES, 2004, p. 15). Trata-se de um visível que se torna opaco por sua proximidade. Dar visibilidade ao visível é, dessa forma, lançar luzes sobre essa opacidade e mostrar aquilo que de tão próximo, tão ligado, indescritivelmente perto, não o conseguimos perceber. Assim, buscamos fazer ver o que já vemos, mas que não percebemos que o vemos, justamente por estar "muito na superfície das coisas" (FOUCAULT, 2013, p. 152).

Ainda, nosso olhar minucioso também não buscou uma origem, não foi em busca da "primeira vez" em que a Modelagem foi dita. A busca por uma origem é "[...] se esforçar para recolher nela a essência exata da coisa, sua mais pura possibilidade, sua identidade cuidadosamente recolhida em si mesma" (FOUCAULT, 2011, p. 17). O olhar que lançamos sobre o material analítico não buscou uma essência para a Modelagem, nem o que é esse discurso, nem qual é a sua origem. Em outras palavras, mapeamos as proveniências, na forma de condições de possibilidade para a sua emergência. Esse mapeamento deu visibilidade ao visível que estava opaco nas dispersões dos enunciados que dizem respeito à emergência do discurso.

'Proveniência' é o termo utilizado por Foucault e que também foi utilizado por Nietzsche, para contrapor suas pesquisas históricas às pesquisas de origem. As pesquisas de origem buscam, a partir do presente, voltar ao passado à procura de uma essência inicial, como se, no ato de voltar ao passado, pudessem encontrar a forma "bruta" e imóvel esperando para ser "descoberta" e lapidada. Essas pesquisas parecem "acreditar que as coisas em seu início se encontravam em estado de perfeição; que elas saíram brilhantes das mãos do criador, ou na luz sem sombra da primeira manhã" (FOUCAULT, 2011, p. 18). Contrariamente, Foucault (2013, p. 152) nos diz que não está "à procura desse primeiro 
momento solene a partir do qual, por exemplo, toda a matemática ocidental foi possível. Não retorno a Euclides ou a Pitágoras. São sempre começos relativos que procuro".

Proveniência, ou ascendência, segundo Veiga-Neto (2007), pode ser entendida como origem, em seu sentido fraco, ou seja, como um ponto recuado no tempo, um lugar - ou melhor um não-lugar - de afrontamento, de combate de forças. A pesquisa da proveniência "agita o que se percebia imóvel, ela fragmenta o que se pensava unido; ela mostra a heterogeneidade do que se imaginava em conformidade consigo mesmo" (FOUCAULT, 2011, p. 21).

Entendemos, desse modo, que voltar ao passado não é buscar uma forma bruta, sua essência original, é, sim, arruinar as "essencialidades, negando a existência de um emsi das coisas, mostrando-as como fabricações a partir de elementos dispersos" (ALBUQUERQUE JÚNIOR, 2008, p. 99); é mostrar o combate de forças, agitar o que se percebe imóvel; é buscar areias movediças, estilhaços que foram marginalizados pela história tradicional. Não é "encontrar versões definitivas sobre os fatos, mas desmontar aquelas versões tidas como verdadeiras, tornando outras possíveis, libertando as palavras e as coisas que nos chegam do passado de seu aprisionamento museológico" (ALBUQUERQUE JÚNIOR, 2008, p. 101).

Essa volta ao passado, à sua proveniência, nos possibilitou mapear as condições de possibilidade para a emergência desse discurso. A emergência é a entrada das forças em cena, a saída dos bastidores para o teatro (FOUCAULT, 2011), é o vir à tona, o ponto de surgimento do discurso no passado. Ao olhar para o passado é preciso ter cuidado para que não se coloque "um conceito, uma ideia ou um entendimento que é do presente. [...]. Não se deve procurar entender o passado com base em categorias do presente. [...] nunca o presente pode ser o tribunal do passado" (VEIGA-NETO, 2007, p. 60-61).

\section{3 À espreita da emergência}

As duas últimas décadas têm mostrado que o ensino de modo geral e, mais particularmente, o ensino de matemática, está atravessando uma de suas crises mais sérias com relação ao binômio ensino-aprendizagem. A crise no ensino de matemática tem reflexos em todos os níveis de ensino seja $1^{\circ}, 2^{\circ}$ ou 3o graus (BURAK, 1987, p. 12, grifos nossos).

As leituras cuidadosas e minuciosas do material empírico deram visibilidade a algumas enunciações que sinalizavam a existência de uma crise no ensino de Matemática, no período que compreende as décadas de 1970 a 1990. Essa crise é evidenciada e constituída a partir de dois enunciados, que, apesar de distintos, guardam entrelaçamentos entre si: (i) os alunos têm dificuldade na aprendizagem da Matemática e (ii) a Matemática é distante da realidade.

Esses enunciados evidenciavam e justificavam as atividades de Modelagem como uma possibilidade para amenizar tal crise. O seu uso possibilitaria que o ensino de Matemática caminhasse em paralelo com a aprendizagem dos alunos e, também, serviria como uma estratégia para mostrar a utilidade dessa disciplina a partir de atividades que a relacionassem com a realidade dos alunos. Dito de outra forma, a emergência da Modelagem, no âmbito das preocupações educacionais, estaria relacionada com a possibilidade de amenizar a dificuldade na aprendizagem da Matemática e, também, mostrar a sua utilidade a partir de sua vinculação com o real. 
Na próxima seção, problematizamos uma das condições de possibilidade para a emergência da Modelagem Matemática na Educação Matemática a partir do enunciado "os alunos têm dificuldade na aprendizagem da Matemática".

\section{Os alunos têm dificuldade na aprendizagem da Matemática}

As enunciações abaixo dão visibilidade ao enunciado em estudo. Elas sinalizam a dificuldade de aprendizagem da Matemática como um acontecimento que engendrou um campo fértil para que a Modelagem Matemática pudesse emergir como uma possibilidade de superação da crise existente.

[...] embora já se possa perceber que os educadores estão conscientes dos problemas que o aluno tem para atingir o domínio do conhecimento matemático, e das dificuldades que eles enfrentam para compreender e aplicar os conceitos matemáticos quando têm que resolver um problema. E o mais grave é que esta situação parece ocorrer em qualquer dos níveis de ensino (SÁNCHEZ, 1979, p. 3, grifos nossos).

Professores de 5 a a 8 ${ }^{a}$ séries reclamando do embasamento matemático dos alunos egressos de 19 a $4^{a}$ séries; professores do $2^{\circ}$ grau reclamando dos alunos oriundos do 1 grau e, finalmente, professores dos cursos de licenciatura e bacharelado descontentes com o nível de conhecimento matemático dos alunos de 2o grau (BURAK, 1987, p. 12, grifos nossos).

Tornou-se fato corriqueiro professores de níveis mais avançados alertarem para o conhecimento matemático dos egressos dos niveis anteriores, dizendo que eles não possuem base suficiente para acompanharem determinada série $e$, desse modo, ele, professor, perde muito tempo para "recuperá-los" (BURAK, 1987, p. 12, grifos nossos).

Os professores desse curso perceberam que os alunos, embora fossem professores de Cálculo de instituições de ensino superior, praticamente de todo o país, na sua grande maioria, não sabiam quase nada de Cálculo. O que fazer? Foi nascendo a ideia de se fazer uma mudança na estratégia de aprendizagem, pois já haviam feito cursos de Cálculo e não haviam aprendido; transmitir os mesmos conteúdos na esperança de que dessa vez aprendessem, não era uma estratégia racional (GAZZETTA, 1989, p. 88, grifos nossos).

O ensino de Matemática está atravessando uma de suas crises mais sérias com relação ao binômio ensino-aprendizagem. As enunciações evidenciam que essa dificuldade de aprendizagem parecia ocorrer em qualquer dos níveis de ensino, visto que havia sempre uma reclamação por parte dos professores sobre essa dificuldade e, também, uma busca por culpados, ou seja, professores de 5a a $8^{a}$ séries reclamando do embasamento matemático dos alunos egressos de $1 \underline{a}$ a $4 \underline{a}$ séries; professores do 20 grau reclamando dos alunos oriundos do 1o grau e, finalmente, professores dos cursos de licenciatura $e$ bacharelado descontentes com o nível de conhecimento matemático dos alunos de 2 grau. Consequentemente, foi nascendo a ideia de se fazer uma mudança na estratégia de aprendizagem, ou seja, transmitir os mesmos conteúdos na esperança de que dessa vez aprendessem, não era uma estratégia racional. 
Essa busca por culpados, sendo eles os professores dos anos anteriores, evidencia que os conteúdos matemáticos obedecem a uma hierarquia, ou seja, o professor não consegue ensinar Matemática para seus alunos porque eles não aprenderam os conteúdos ensinados anteriormente. Esses conteúdos seriam pré-requisitos para a aprendizagem dos conteúdos matemáticos da série atual, enfatizando, desta maneira, que o ensino de Matemática é linear e sequencial. Talvez, por acreditar-se que o ensino dos conteúdos matemáticos seja hierárquico é que o enunciado que diz respeito à dificuldade de aprendizagem de Matemática tenha englobado todos os níveis de ensino.

Essa discussão é problematizada por Neves (2015). O autor evidencia e problematiza "a falta de base" como um dos problemas ligados à dificuldade de aprendizagem dos alunos.

Tomando os questionamentos de professores e alunos foi possível constar que os problemas de aprendizagem dos alunos, que estão no ensino médio, estão fortemente ligados a falta de domínio dos conteúdos de Ensino Fundamental, sendo estes a base para que os alunos tenham êxito em matemática, bem como em outras disciplinas que se servem da matemática. Dessa forma, os conteúdos acumulam-se ano após ano e, como consequência dificultam a aprendizagem em cursos subsequentes e o desenvolvimento de competências básicas, o que leva o aluno a deparar-se com obstáculos na disciplina Matemática (NEVES, 2015, p. 152, grifos nossos).

Justifica-se a dificuldade de aprendizagem de Matemática, assim, pela via do discurso de que os alunos não têm base, porque não aprenderam os conteúdos ensinados nos anos anteriores. Desta maneira, os conteúdos não aprendidos acumulam-se e, como consequência, os alunos encontram dificuldade nos cursos subsequentes. Essa busca pelos culpados pela dificuldade dos alunos na aprendizagem de Matemática apresenta regularidade discursiva com enunciados pronunciados na contemporaneidade:

As considerações dos pesquisadores evidenciam o que temos presenciado em nosso cotidiano escolar e fora dele: a busca por culpados. No Ensino Fundamental, acusam-se os professores dos Anos Iniciais; estes são responsabilizados pelos do Ensino Médio, que, por sua vez, são apontados pelos que lecionam nas universidades. É o efeito dominó. (NEVES, 2015, p. 54, grifos nossos).

Acredita-se que os alunos têm dificuldade com a aprendizagem de Matemática porque estes não aprenderam os conteúdos que deveriam ter aprendido nas séries anteriores, culpando-se os professores dos anos antecedentes por essa situação. Desse modo, podemos inferir que o enunciado problematizado por nós e que diz respeito à dificuldade na aprendizagem da Matemática possui campo associado ao enunciado problematizado por Neves (2015), qual seja: "os alunos não aprendem matemática por 'falta de base'".

O enunciado problematizado por Neves (2015), e que se encontra naturalizado na Educação Matemática, está relacionado à forma como o conhecimento matemático foi se constituindo: de modo sequencial e obedecendo a hierarquias. Ou seja, "para entender determinados conteúdos, os estudantes precisam dominar outros que os antecedem" (NEVES, 2015, p. 121). Sendo assim, o enunciado "os alunos não aprendem matemática por 
falta de base", para Neves (2015), também se entrelaça a outros dois enunciados: "o conhecimento matemático (escolar) é hierarquizado" e "o currículo escolar é hierarquizado". Referente ao enunciado "o conhecimento matemático (escolar) é hierarquizado, Neves (2015, p. 127, grifos nossos) enfatiza que:

O fato de o ensino da Matemática acontecer do mais simples ao mais complexo, tendo sua aprendizagem condicionada a conhecimentos anteriores, reforça as enunciações sobre a 'falta de base' não apenas no âmbito escolar, mas fora dela. A própria história da Matemática busca demonstrar que, o conhecimento matemático começou com as necessidades básicas das civilizações em quantizar o seu entorno: em seguida, evoluiu para as esferas mais complexas desse pensamento (axiomatização, teoremas, sistemas computacionais, etc.).

Referente ao entrelaçamento do enunciado "os alunos não aprendem matemática por falta de base" com o enunciado "o currículo escolar é hierarquizado", Henriques (1998) argumenta que o currículo escolar foi formado de modo compatível ao modelo racionalpositivista fundado nas noções de norma, sequência e disciplina. Com relação à norma, o currículo apresenta-se de forma prescritiva, impondo obediência, sem possibilidade de desvios. A noção de sequência enfatiza que o currículo supõe uma ordenação de conteúdos em consonância com uma sequência predefinida. A disciplina, por sua vez, organiza os conteúdos dentro de matrizes disciplinares.

Ao se considerar que essas noções - norma, sequência e disciplina - contribuem para a dificuldade de aprendizagem dos alunos, a Modelagem poderia apresentar-se como possibilidade para amenizar essa situação, pois, segundo Caldeira (1998), a Modelagem trabalharia com um currículo em espiral, no qual os conteúdos das séries anteriores retornariam, caso necessário, para a discussão das atividades presentes. Desta maneira, não haveria necessariamente uma forma linear e hierárquica para o ensino dos conteúdos. As citações a seguir demonstram em que consiste o ensino de Matemática com foco na Modelagem, baseado no currículo em espiral.

Na concepção de ensino da professora, não poderíamos trabalhar os números decimais juntamente com a geometria e mais do que isso, teríamos que trabalhar primeiro as frações e só depois os números decimais. Na concepção de ensino onde se trabalha com os fatos da realidade, muitas vezes isto não é possível. No nosso caso, trabalhamos os números decimais juntamente com a geometria, sem antes termos trabalhado as frações, isto tudo decorrente da necessidade de determinados conceitos para que pudéssemos responder a um questionamento que foi elaborado pelos alunos a partir dos fatos. Aqui o currículo aparece em forma de espiral (CALDEIRA, 1998, p. 177, grifos nossos).

É uma prática de ensino onde não há a sequência rígida de conteúdo, verificada no ensino tradicional, e cada tópico do programa estudado é tratado com profundidade devida ao nível e à série. Outro aspecto a ressaltar nesta prática de ensino através da Modelagem é aquele em que a situação-problema determina o conteúdo a ser estudado e isto parece ser muito positivo, pois a sucessão de situações-problema experimentadas e vivenciadas pelo aluno acabarão por formar-Ihe um espírito crítico e aberto às novas experiências (BURAK, 1987, p. 18, grifos nossos). 
Os conteúdos poderão repetir-se várias vezes no transcorrer das múltiplas atividades e em diferentes ocasiões, mais ou menos como a forma preconizada por Bruner (1978, p. 48), quando trata do currículo em espiral. A oportunidade que o estudo com modelos proporciona de um mesmo conteúdo matemático pode ser visto e aplicado às várias situações distintas permite fixar as ideias fundamentais, podendo contribuir de maneira significativa para a percepção $e$ compreensão da importância da matemática no cotidiano da vida de cada indivíduo, seja ou não ele matemático (BURAK, 1987, p. 44, grifos nossos).

Outro ponto que consideramos importante nesta prática educativa é que alguns conteúdos poderão repetir-se várias vezes, no transcorrer das múltiplas atividades inerentes ao problema proposto. Além disso, não existe uma rigidez na sequência dos conteúdos, pois estes são determinados pelo problema ou conjunto de problemas (BURAK, 1992, p. 95, grifos nossos).

As enunciações mostram que, no ensino de Matemática caracterizado pela hierarquia, teríamos que trabalhar primeiro as frações e só depois os números decimais, obedecendo aos pré-requisitos estabelecidos. Porém, em atividades de Modelagem é possível trabalhar os números decimais juntamente, sem antes ter trabalhado as frações. Consequentemente, o ensino de Matemática apareceria como uma nova prática, em que não há a sequência rígida de conteúdo, eles [os conteúdos] são determinados pelo problema ou conjunto de problemas. Sendo assim, nas atividades de Modelagem o currículo aparece em forma de espiral.

As enunciações acima evidenciam que há um embate de forças entre o currículo fundado nas noções de norma, sequência e disciplina e o currículo apresentado em forma de espiral. Em outros termos, o uso de atividades envolvendo Modelagem traria para o ensino de Matemática uma nova prática, reconfigurando a forma como o ensino dos conteúdos matemáticos vinha sendo realizada. O currículo continuaria sendo cumprido, porém, a maneira como ele seria trabalhado romperia com a linearidade e os pré-requisitos. Isso ocorreria porque nem sempre ao se trabalhar com fatos da realidade os conteúdos se dão de modo organizado sequencialmente. Seria a situação da realidade e o problema a ser resolvido que determinariam quais conteúdos seriam necessários para a resolução da atividade.

Quando trazemos problemas da realidade de fora da escola para a sala de aula, é possível que os conceitos desse currículo não surjam de forma linearmente bem comportada, mas de uma forma espiral em que, muitas vezes, temos de fazer o movimento de ir e de voltar, o que pode acontecer de termos de 'misturar' os elementos que estão dentro das gavetas (MEYER, CALDEIRA, MALHEIROS, 2011, p. 40, grifos nossos).

O discurso da Modelagem não seria guiado pela sequência, hierarquia e linearidade dos conteúdos. Ele seria, portanto, uma possibilidade para 'resolver' ou 'diminuir' as dificuldades dos alunos, se essas fossem decorrentes da 'falta de base'. Porém, a sua implementação ${ }^{4}$ em sala de aula se tornaria um paradoxo, ou seja, o currículo em forma de espiral possibilitaria amenizar as dificuldades de aprendizagem, mas os professores

\footnotetext{
${ }^{4} \mathrm{Na}$ década de 1990, a discussão sobre a implementação da Modelagem em sala de aula estava ligada à discussão curricular. Na contemporaneidade, há pesquisas que evidenciam outras dificuldades. Para aprofundamento da questão, ver Magnus (2012), Silveira e Caldeira (2012) e Ceolim (2015).
} 
sentir-se-iam impelidos a cumprir o currículo que foi constituído hierarquicamente e ensinar os conteúdos também de forma linear e hierárquica. Resumindo, "a necessidade de cumprir o 'programa' parece ser um dos principais obstáculos para a implementação da Modelagem na escola" (FIORENTINI, 1996, p. 9).

A grande preocupação para alguns professores e coordenadores de área, quando se trata da Modelagem, é com relação ao programa estabelecido para a série. Dentro da concepção atual da Matemática, a preocupação com o programa a ser cumprido é muito grande (BURAK, 1992, p. 296, grifos nossos).

Sendo o currículo um empecilho para a aplicação da Modelagem, alguns autores propõem formas para adequar as atividades para que ele seja cumprido. Essas adequações nas atividades não significam que os conteúdos sejam abordados sequencial e linearmente, mas que 'garantirão', de certa forma, que sejam cumpridos e ensinados os conteúdos previstos.

A modelação é um método que utiliza-se (sic) da essência da Modelagem Matemática para ensinar matemática, em cursos que tem (sic) um programa (currículo) pré-determinado. Este método difere da Modelagem no ensino, pois utiliza-se de um único tema para extrair o conteúdo matemático programático (BIEMBENGUT, 1997, p. 107, grifos nossos).

A Modelação na Graduação utiliza-se de um tema/assunto único, para nortear o desenvolvimento do conteúdo (parte ou até mesmo todo) do programa, onde as questões sobre o tema e devida ordem para respondê-las, são definidas pelo professor, previamente preparadas. Além disso, é proposto aos alunos a elaboração de um trabalho - Modelo Matemático - porém, de forma mais dirigida (BIEMBENGUT, 1997, p. 112, grifos nossos).

Os Modelos elaborados pelos grupos devem fazer uso no mínimo de uma parte do conteúdo programático da disciplina. Caso algum grupo, para resolver uma questão, necessite de algum tópico matemático que não faça parte do programa e que não seja de conhecimento do grupo, o professor pode atender, exclusivamente, ensinando-o ou induzindo-o à pesquisa, mantendo-se como orientador (BIEMBENGUT, 1997, p. 117, grifos nossos).

O grande desafio experimentado ao se propor a Modelagem, como um método alternativo para o ensino de Matemática, nos cursos regulares de 1 e 2 graus, é encontrar uma ou mais formas alternativas no sentido de compatibilizar os conteúdos previstos para determinada série e o conteúdo possível, trabalhado com a Modelagem Matemática. De 1a a 6a séries a Modelagem, através da maioria dos temas até então trabalhados, contempla, de forma muito mais satisfatória, os conteúdos previstos (BURAK, 1992, p. 296-297, grifos nossos).

Nas últimas séries do 19 grau, $7 \underline{a}$ e 8aa, alguns conteúdos, como por exemplo polinômios, números inteiros relativos, inequações do 1 o grau, podem não ser contemplados, dependendo do tema trabalhado. Uma forma encontrada para sanar essa dificuldade foi trabalhar parte da carga horária da disciplina de Matemática com o tema sugerido pelos alunos e, parte da carga horária, o professor usar para tratar dos conteúdos não contemplados no tema desenvolvido. Com a realização de várias experiências, o professor vai 
encontrando situações em que esses conteúdos possam ser tratados (BURAK, 1992, p. 297, grifos nossos).

Alguns conteúdos, não contemplados no desenvolvimento da Modelagem, podem ser contemplados com outro tema, ou ainda, ser tratados de maneira adotada por alguns professores onde parte da carga destinada à disciplina de Matemática é trabalhada com os conteúdos não abordados na experiência com a Modelagem (BURAK, 1992, p. 302, grifos nossos).

Isso reforça a dificuldade de se utilizar a Modelagem Matemática, já que é a preocupação com cumprir um programa pré-estabelecido que tem sido, em geral, o fio condutor das atividades programadas pelo professor. $O$ que proponho neste caso é que o professor procure realizar atividades de modelagem, refletindo a cada passo sobre os conteúdos que vão sendo trabalhados $e$ intercalando essas atividades com momentos explícitos de construção de conteúdos que lhe pareçam necessários e que porventura não tenham surgido no processo (ANASTÁCIO, 1990, p. 100, grifos nossos).

Como cumprir o currículo a partir de atividades de Modelagem? É possível cumprilo? De que maneira? As enunciações acima evidenciam que nas atividades de Modelagem é preciso encontrar uma ou mais formas alternativas no sentido de compatibilizar os conteúdos previstos para determinada série e o conteúdo possível. Os conteúdos não contemplados na atividade podem ser contemplados com outro tema. Para o cumprimento dos conteúdos previstos é importante que o professor, ao realizar atividades de modelagem, reflita a cada passo sobre os conteúdos que vão sendo trabalhados e intercale essas atividades com momentos explícitos de construção de conteúdos. Embora os conteúdos não apareçam de forma sequencial, é importante que haja sistematização e organização das atividades de tal forma que os conteúdos previstos sejam estudados a partir dessas atividades.

Em efeito, a análise empreendida mostrou que a emergência do discurso da Modelagem está relacionada com a maneira como o currículo estava sendo implementado naquele momento, a partir das noções de norma, sequência e disciplina. Por causa dessa estrutura curricular, a justificativa para a não aprendizagem da Matemática estava relacionada com a "falta de base" dos alunos, com os conteúdos que não foram aprendidos nos anos anteriores. Desta maneira, a emergência da Modelagem como alternativa para o ensino dos conteúdos matemáticos, a partir de situações da realidade do aluno, traria uma nova forma de abordagem do currículo, ou seja, os conteúdos apareceriam de acordo com a necessidade para a resolução da atividade. Em alguns casos, seria necessário algumas idas e voltas, de modo que alguns conteúdos poderiam aparecer mais vezes, permitindo "fixá-los".

De acordo com o material analítico, no discurso da Modelagem o currículo não seria hierárquico, linear e sequencial. A lógica curricular que guiaria as atividades de Modelagem seria a imprevisibilidade, a casualidade, a eventualidade, a contingência, o caos. A emergência da Modelagem se dá nesse deslocamento, da ordem para a desordem curricular. Assim sendo, a desordem penetraria, perpassaria e modificaria, de certa maneira, a ordem estabelecida. 


\section{Da emergência de outras inquietações...}

O enunciado dá visibilidade à busca pelos culpados pela dificuldade dos alunos com a aprendizagem dos conteúdos matemáticos. Ou seja, o "professor atual" não conseguiria ensinar Matemática aos seus alunos porque eles não aprenderam os conteúdos que deveriam ter aprendido anteriormente, com o "professor anterior", evidenciando que os conteúdos matemáticos obedecem a uma ordem hierárquica. Consequentemente, a não aprendizagem de um conteúdo dificultaria a aprendizagem de outro, demonstrando, assim, relação de dependência entre os conteúdos.

Essa situação se tornou um campo fértil para que o discurso da Modelagem emergisse como uma possibilidade para amenizar essa crise no ensino de Matemática. De acordo com o material analítico, nas atividades de Modelagem os conteúdos matemáticos não seriam ensinados de forma sequencial. A partir de situações da realidade, os conteúdos apareceriam conforme a necessidade para a resolução da atividade. O discurso da Modelagem operaria um deslocamento na estrutura curricular, de forma que as práticas seriam guiadas pela contingência, pelo caos em detrimento da ordem, da hierarquia, da sequência e da norma.

A Modelagem proporcionaria outras possibilidades para o processo de ensino e aprendizagem dos conteúdos escolares, ou seja, ela operaria com outras estratégias para ensinar Matemática, partindo do pressuposto de que essa nova estratégia pudesse cumprir a meta da aprendizagem. Porém, ela não criaria fissuras ou trincas no discurso curricular; pelo contrário, ela legitimaria e buscaria táticas "eficientes" de ensino e aprendizagem. Desta forma, a Modelagem funcionaria como uma engrenagem na busca pelo melhor funcionamento daquilo que está posto. Ou seja, como fazer os alunos aprenderem aquilo que precisamos ensinar, a partir do discurso curricular e da matemática escolar. 0 deslocamento que a Modelagem proporcionaria no discurso curricular se daria na ordem estrutural. Ela [a Modelagem] não problematiza a matemática que é colocada em circulação pelo currículo.

Além disso, "preparado, escrito, editado e divulgado pelo Estado brasileiro, o currículo nacional é uma de suas formas privilegiadas de controle e regulação, funcionando como princípio e método para racionalizar as próprias práticas governamentais" (CORAZZA, 2001b, p. 81). Estaria a Modelagem, a partir disso, colaborando com essas formas de controle e regulação da população escolar? Seria a Modelagem um mecanismo de legitimação das práticas governamentais? Seria a Modelagem uma engrenagem da maquinaria destinada a operar com as verdades que constituem o currículo? Estaria ela a serviço do discurso curricular? O discurso da Modelagem, ao legitimar o currículo, estaria contribuindo para uma "nova, abrangente e eficaz tática de governo do Estado" (CORAZZA, 2001b, p. 80)?

\section{REFERÊNCIAS}

ALBUQUERQUE JÚNIOR, D. M. Michel Foucault e a Mona Lisa ou como escrever a história com um sorriso nos lábios. In: RAGO, M.; VEIGA-NETO, A. (orgs). Figuras de Foucault. 2 ed. Belo Horizonte: Autêntica, 2008. 
ANASTÁCIO, M. Q. A. Consideração sobre a Modelagem Matemática e a Educação Matemática. 111 f. Dissertação (Mestrado em Educação Matemática). Programa de Pós-Graduação em Educação Matemática. Universidade Estadual Paulista. Rio Claro, SP: 1990.

ARTIÈRES, P. Dizer a Atualidade: O trabalho de diagnóstico em Michel Foucault. In: GROS, Frédéric (org). Foucault: a coragem da verdade. São Paulo, Parábola Editorial, 2004.

BIEMBENGUT, M. S. Qualidade no ensino de matemática na engenharia: uma proposta curricular e metodológica. 1997. 196 p. Tese (Doutorado em Engenharia de Produção) - Departamento de Engenharia de Produção e Sistemas, Universidade Federal de Santa Catarina, Florianópolis, 1997.

BURAK, D. Modelagem Matemática: uma metodologia alternativa para o ensino de matemática na 5a série. Dissertação (Mestrado em Educação Matemática). Programa de Pós-Graduação em Educação Matemática. Universidade Estadual Paulista Júlio Mesquita Filho, Rio Claro, 1987.

. Modelagem Matemática: ações e interações no processo de ensino-aprendizagem. Tese (Doutorado em Educação). Programa de Pós-Graduação em Educação. Faculdade de Educação da Universidade Estadual de Campinas, Campinas, 1992.

CALDEIRA, A. D. Educação Matemática e Ambiental: um contexto de mudança. Tese (Doutorado em Educação). Programa de Pós-Graduação em Educação. Universidade de Campinas, Campinas, 1998.

CORAZZA, S. M. "Como dar uma aula?" Que pergunta é esta? In: MORAES, Vera Regina Pires de. (Org.). Melhoria do ensino e capacitação docente: programa de aperfeiçoamento pedagógico. Porto Alegre: Ed. UFRGS, 1996, p. 57-63. 2001b.

O que quer um currículo? Pesquisas pós-críticas em educação. Petrópolis, RJ: Vozes,

. Labirintos da pesquisa, diante dos ferrolhos. IN: COSTA, M. V (org). Caminhos

Investigativos I: novos olhares na pesquisa em educação. 3 ed. Rio de Janeiro: Lamparina, 2007.

. Didaticário de criação: aula cheia, antes da aula. Anais... XVI ENDIPE - Encontro Nacional de Didática e Práticas de Ensino - UNICAMP - Campinas, 2012.

DUARTE, C. G. A "realidade" nas tramas discursivas da educação matemática escolar. 198 f. Tese (Doutorado em Educação). Universidade do Vale do Rio dos Sinos: São Leopoldo, 2009.

FIORENTINI. Estudo de algumas tentativas pioneiras de pesquisa sobre o uso da modelagem matemática no ensino. In: ICME, 8, 1996, Sevilha. Anais... Sevilha: ICME, 1996.

FOUCAULT, M. Nietzsche, a genealogia e a história. In: FOUCAULT, M. Microfísica do poder. Rio de Janeiro, Graal, 2011.

. Michel Foucault explica seu último livro. In: Arqueologia das ciências e história

dos sistemas de pensamento. Ditos e Escritos II. Organização e seleção de textos Manoel Barros da Motta: tradução Elisa Monteiro. 3 ed. Rio de Janeiro: Forense Universitária, 2013. 
. A Arqueologia do Saber. Trad. Luiz Felipe Baeta Neves. 8aㅡ ed. 3a tiragem. Rio de Janeiro: Forense Universitária, 2014a.

. História da sexualidade 2: o uso dos prazeres. Trad. Maria Thereza da Costa Albuquerque. 1a ed. São Paulo: Paz e Terra, 2014b.

GAZZETTA, M. A Modelagem como Estratégia de Aprendizagem da Matemática em Cursos de Aperfeiçoamento de Professores. Dissertação (Mestrado em Educação Matemática). Programa de Pós-Graduação em Educação Matemática. Universidade Estadual Paulista, Rio Claro, 1989.

GREGOLIN, M. do R. V. O enunciado e o arquivo: Foucault (entre)vistas. In: SARGENTINI, V.; NAVARRO-BARBOSA, P. (org). Foucault e os domínios da linguagem: discurso, poder, subjetividade. São Carlos: Claraluz, 2004.

HENRIQUES, M. S. O pensamento complexo e a construção de um currículo não-linear. 21a Reunião Anual da ANPEd (Caxambu, MG, setembro de 1998), no GT Currículo, 1998.

LARROSA, J. Notas sobre a experiência e o saber de experiência. Revista Brasileira de Educação, n. 19. Jan/Fev/Mar/Abr 2002.

MACHADO, R. Foucault, a ciência e o saber. 3a ed. ver. e ampliada. Rio de Janeiro: Jorge Zahar, 2007.

MAGNUS, M. C. M. Modelagem Matemática na Educação Matemática Brasileira: histórias em movimento. 2018. 227 p. Tese (Doutorado em Educação) - Programa de Pós-Graduação em Educação, Universidade Federal de São Carlos, São Carlos, 2018.

MEYER, J. F. da C. de A.; CALDEIRA, A. D.; MALHEIROS, A. P. dos S. Modelagem em Educação Matemática. Belo Horizonte: Autêntica, 2011.

NEVES, J. C. M. O enunciado "os alunos não aprendem matemática por 'falta de base" em questão. 177 f. Tese (Doutorado em Educação). Programa de Pós-Graduação em Educação, Universidade do Vale do Rio dos Sinos, São Leopoldo, 2015.

QUARTIERI, M. T. A Modelagem Matemática na educação básica: a mobilização do interesso do aluno e o privilegiamento da matemática escolar. 2012. 199 f. Tese (Doutorado em Educação). Universidade do Vale do Rio dos Sinos, São Leopoldo, 2012.

SÁNCHEZ, J. E. P. Estratégia combinada de módulos instrucionais e modelos matemáticos interdisciplinares para ensino-aprendizagem de matemática a nível de segundo grau: um estudo exploratório. 305 f. Dissertação (Mestrado em Educação). Pontifícia Universidade Católica do Rio de Janeiro, Rio de Janeiro, 1979.

VEIGA-NETO, A. Foucault e a Educação. 2 ed. 1 reimp. Belo Horizonte: Autêntica, 2007. 